upf. $\begin{array}{ll}\text { Universitat } \\ \text { Pompeu Fabra } \\ \text { Barcelona }\end{array} \quad \begin{aligned} & \text { Department } \\ & \text { of Economics and Business }\end{aligned}$

Economics Working Paper Series

Working Paper No. 1478

\title{
Heterogeneous consumers and fiscal policy shocks
}

\author{
Emily Anderson \\ Atsushi Inoue \\ Barbara Rossi
}

Updated version: December 2015

(February 2011) 


\title{
Heterogeneous Consumers and Fiscal Policy Shocks
}

\author{
Emily Anderson \\ Researcher \\ Private Consulting \\ Email: \\ anderebl@gmail.com \\ Atsushi Inoue \\ Full Professor \\ Dept. of Economics \\ Vanderbilt University \\ Email: \\ atsushi.inoue@vanderbilt.edu \\ Barbara Rossi* \\ Full Professor \\ Dept. of Economics \\ ICREA-Univ.Pompeu Fabra, \\ Barcelona GSE, and CREI. \\ Email: \\ barbara.rossi@upf.edu
}

First Draft: February 2011. This Draft: December 2015

Abstract: This paper studies empirical facts regarding the effects of unexpected changes in aggregate macroeconomic fiscal policies on consumers that differ depending on individual characteristics. We use data from the Consumption Expenditure Survey to estimate individual-level responses and multipliers for government spending. We find that unexpected fiscal shocks have substantially different effects on consumers depending on their income and age levels: the wealthiest individuals tend to behave according to predictions of standard RBC models, whereas the poorest ones behave according to standard IS-LM (nonRicardian) models, most likely due to credit constraints. Furthermore, government spending policy shocks tend to decrease consumption inequality. 
*Corresponding author: Barbara Rossi, CREI, Universitat Pompeu Fabra, c. Ramon Trias Fargas 25-27, Mercè Rodoreda bldg., 08005 Barcelona, Spain.

Acknowledgments. Preliminary results in this paper were formally presented by Emily Anderson on Sept. 8th, 2010, at Duke University and by Barbara Rossi at Ohio State University in 2010. We thank V. Ramey and D. Romer for sharing their data and replication codes, the editor, K. West, and J. Gali', J. Leahy, K. Mertens, S. Schmitt-Grohe', S. Zubairy and seminar participants at the 2011 CEA, the 2011 Exchange Rate Conference at Duke U., the 2012 SED Conference, the Federal Reserve Bank of St. Louis, Duke, UPF, Goethe and Ohio State Universities for comments. The authors gratefully acknowledge financial support from NSF grants \# 1022159 and 1022125.

J.E.L. Codes: E4, E52, E21, H31, I3, D1.

Keywords: fiscal policy shocks, heterogeneous agents, welfare, consumption, consumption expenditure survey. 


\section{INTRODUCTION}

Most of the literature studying the effects of fiscal policy shocks relies on the representative agent paradigm. The assumption of a representative agent is generally made for technical simplicity, since the solution of dynamic models with heterogeneous agents is computationally challenging. However, the study of aggregate data might lead to an incorrect evaluation of economic theories. For example, Attanasio and Weber (1993) demonstrate that the use of microeconomic data can overturn rejections of consumer intertemporal optimization models based on aggregate data. In addition, the assumption comes at the cost of preventing the analysis of important questions, such as whether economic policies equally affect individuals with different characteristics, whether they influence inequality, or what are the macroeconomic consequences of aggregate fluctuations on the welfare of individuals that differ in their consumption patterns. In other words, while the representative agent assumption allows to study how the average value of macroeconomic variables are affected by economic policies, it does not allow to study how these policies affect the distribution of such variables across households.

This paper focuses on studying the effects of unexpected changes in aggregate fiscal policies on consumers that are allowed to differ depending on their individual characteristics. We ask the questions: "Do fiscal shocks affect individuals differently? And, if so, how?". Fiscal policy analysis is an especially important area of macroeconomics since it has direct implications for consumers' welfare. The literature has extensively studied the effects of government spending and tax policy shocks on aggregate macroeconomic variables; one of the approaches, which we focus on, has been narrative - see Ramey and Shapiro (1998) and 
Ramey $(2009,2011 \mathrm{a}) .{ }^{1}$ The narrative approach uses narrative records (such as presidential speeches and newspapers) to identify the timing and magnitude of major fiscal changes, and identifies fiscal shocks as those changes that were taken for reasons exogenous to the business cycle. However, since these analyses focus on aggregate data, by construction they only provide an estimate of the average response of aggregate macroeconomic variables to fiscal shocks (on average across individuals), while being uninformative regarding the heterogeneity across individual responses. Realistically, fiscal shocks may affect individuals differently depending on their individual-specific characteristics, such as income and age. Studying whether this is the case, and who gains and who loses from unexpected changes in government spending policy is the main focus of this paper.

We find that unexpected government spending shocks have different effects on consumers depending on their income and age levels. Our empirical evidence is based on a narrative approach, and in particular a Vector Autoregressive (VAR) model, as in Ramey (2011a). By using a Structural VAR (SVAR) model where the shock is ordered first, we ensure that the shock series is orthogonal to past information contained in the other variables included in the VAR; at the same time, we allow variables other than the shock to contemporaneously react to the shock itself. Our main finding is that individuals whose consumption levels are most negatively affected by a government spending policy shock (i.e. an unexpected increase in government spending) are the wealthiest and working-age individuals, whereas consumption of the poorest increases the most. Thus, positive government spending policy shocks tend

\footnotetext{
${ }^{1}$ See also Edelberg, Eichenbaum, and Fisher (1999), Burnside, Eichenbaum, and Fisher (2004), Cavallo (2005), Perotti (2007) and Rossi and Zubairy (2011) for related papers. Ramey (2011b) provides an extensive review of the literature.
} 
to decrease consumption inequality.

Regarding the economic interpretation of our results, our paper is related to Galí et al. (2006). Galí et al. (2006) show that a calibrated Keynesian model with sticky prices and rule-of-thumb consumers can generate an increase in consumption when government spending increases. Our results provide further empirical support to their analysis by showing that the poorest individuals, i.e. the ones that are more likely to be credit constrained, have a positive consumption response to fiscal policy shocks; on the other hand, the richest individuals' consumption responds negatively. Overall, the response of the whole population will depend on which of the two prevails.

This paper's analysis is closely related to the large literature on the effects of government spending on macroeconomic aggregates, such as Ramey (2009, 2011a). While this literature focuses on the effects of shocks on aggregate data, we focus instead on effects on individual consumption by allowing individuals to be heterogeneous. Our research is also related to Owyang and Zubairy (2009) and Nekarda and Ramey (2011); while we focus on heterogeneity across individual consumers, Owyang and Zubairy (2009) focus on heterogeneity across states and Nekarda and Ramey (2011c) across industries. Furthermore, after a draft of this paper was circulated, we became aware of work by De Giorgi and Gambetti (2012), who study the effects of government spending shocks across income deciles in a VAR that includes Ramey's (2011a) shock as well as the common components of the distribution of CEX consumption across income deciles explained by macroeconomic factors. The factors are extracted from a large dataset of macroeconomic variables. They find empirical results similar to ours; that is, consumption increases for the poorest individuals and decreases for 
rich individuals, while the middle of the distribution responds very little. While the empirical results are similar, their estimation technique substantially differs from ours; furthermore, they do not consider deciles of the distribution based on other characteristics such as age, which we instead investigate. Also, Giavazzi and McMahon (2012) study heterogeneity in household responses in hours worked to shifts in fiscal policy. We instead analyze heterogeneity in household responses to aggregate fiscal shocks identified via a narrative approach in a VAR setting. ${ }^{2}$

\section{DATA DESCRIPTION}

We collect information on consumption and income heterogeneity across individuals by using household consumption expenditure data from the interview portion of the Consumer and Expenditure Survey (CEX), conducted by the Bureau of Labor Statistics. ${ }^{3}$ The measure of government spending shocks we use is the time series developed by Ramey (2011a). We use quarterly data that span 1984:Q1-2008:Q4; the starting date of the sample is determined by the availability of CEX data, whereas the end date is determined by the availability of data on the government spending shocks. This section provides a detailed description of the data.

We follow Lusardi (1996) and focus on nondurable consumption defined as expenditures

\footnotetext{
${ }^{2}$ Other related papers include Schmitt-Grohe' and Uribe (2012), who study the contribution of anticipated shocks to business cycles in US data, including government spending, and Zubairy (2011), who develops a DSGE model with fiscal shocks. Also, see Rios-Rull (1995), Krusell and Smith (1998), Heathcote (2005) for theoretical models of heterogeneous agents; our focus is, instead, empirical.

${ }^{3}$ U.S. Department of Labor, Bureau of Labor Statistics, Consumer Expenditure Survey, Interview (Diary) Survey.
} 
on food, alcoholic beverages, tobacco, utilities, personal care, household operations, public transportation, gas and motor oil, and miscellaneous expenses. We focus on nondurable consumption rather than durable because the latter is more similar to an investment decision. The measure of income we use is the household income after taxes for the 12 months before the survey is taken. The household is identified with the head of the household. We drop households with missing data or non-positive consumption or income data. Also, we drop 1986:Q1 due to missing data. An additional concern is the presence of measurement error in the data, in particular for income data reported in the CEX (Lusardi, 1996). Our procedure involves constructing pseudo-panels by averaging individuals belonging to groups identified by individual-specific characteristics; thus, our procedure attenuates idiosyncratic measurement error by averaging individual-level consumption data. Individual-level income data, which are subject to stronger measurement error, are used only to construct income quintiles, thus not raising strong concerns about the effects of measurement error in income in our main results.

Our measure of consumption is the log of real per capita consumption expenditures. To construct this measure, first we seasonally adjust the data by using the X-12 ARIMA seasonal adjustment procedure of the US Census Bureau. ${ }^{4}$ We also divide CEX household data by the number of family members for each household to get a measure of per capita consumption. Finally, we transform CEX consumption in real terms using the nondurables price deflator, as in Ramey (2011a).

\footnotetext{
${ }^{4}$ Our empirical results are similar and even stronger when we consider seasonal adjustment based on a moving average. Details are reported in a Anderson et al. (2015).
} 
We study the effects of government spending identified via a narrative approach. The main advantage of using the narrative approach relative to identifying shocks via SVARs is that the shock is directly identified by using information outside the VAR estimation, and hence does not depend on which variables are included in the VAR nor on identification assumptions. The disadvantage of the narrative approach is that it requires judgment calls when creating the shock variable. To mitigate the latter concern, we use well-established measures and we include the shocks measures in a SVAR to ensure that the shock is uncorrelated with past values of the other macroeconomic variables we consider.

The measure of government spending policy shocks we use is developed by Ramey (2011a). Typically, when studying government spending policy, researchers use defense news shocks since they are the least likely to crowd out private consumption and be affected by demographic changes or the state of the economy. Ramey (2011a) does provide a narrative time series of defense spending news shocks based on studying articles in news sources such as the Business Week magazine. Unfortunately, she shows that the defense news shock does not have good explanatory power for real government spending in our sample period, limited by CEX data availability. She develops an alternative narrative measure of government defense spending shocks based on the Survey of Professional Forecasters (SPF). The SPF shock is the difference between actual real government spending growth and the SPF's forecasted growth. She shows that this measure does have good explanatory power for government spending in the time period that we consider, so we focus on this measure in our paper.

It is important to verify that CEX data are appropriate for our analysis; Anderson et al. (2015) show that empirical results based on aggregate CEX data are very similar to those 
currently reported in the literature, even in the sub-sample we consider and when using a simple VARs with fewer variables than in the literature (which is more appropriate for our analysis, given the small sample constraints in CEX data). Thus, we can use CEX data in our analysis and focus on a small VAR without being too concerned about the potential misspecification induced by the parsimonious number of variables that we consider. However, CEX data have an important advantage relative to NIPA data: they can be disaggregated across individuals, and used to evaluate the extent of heterogeneity in individual consumption responses to policy shocks.

\section{OUR APPROACH}

The CEX is not really a genuine panel, where the same individual is followed over time, but a rotating panel, where individuals remain in the sample only for a limited number of quarters. Deaton (1985) discusses methodologies for adapting the analysis of time series of cross section data to panels using pseudo-panels identified by defining groups of individuals. For our main analysis, we construct a pseudo panel dataset from the CEX by grouping households according to income, although we explore grouping based on age as well. The challenge when defining groups is not to aggregate individuals too much, otherwise we would not observe heterogeneity. On the other hand, we cannot study individuals since each household is only in the survey for four quarters. Thus, we choose group sizes that maintain the heterogeneity while keeping enough households in each group. Income groups are based on income quintiles. Regarding age, households fall into one of five possible groups, defined as: 15-24, 25-34, 35-44, 45-70, and 71-90 year-old individuals.

In order to examine the consequences of a government spending policy shock, we consider 
a three variable VAR inspired by Ramey (2011a), including the SPF fiscal shock, government spending, and consumption. As previously discussed, the VAR is identified with a recursive ordering procedure where the shock is ordered first and consumption last. We estimate the VAR separately for each group $j, j=1, \ldots, J$, where $J$ is the total number of groups $(J=5$ in our analysis). The household groups are identified based on the individual characteristics previously discussed (income and age). We also consider specifications that include or exclude a constant and a quadratic time trend. Specifically, our VAR is:

$$
A^{j}(L) Z_{t}^{j}=K^{j}+D_{1}^{j} t+D_{2}^{j} t^{2}+U_{t}^{j}
$$

where $Z_{t}^{j}$ is a vector containing the SPF shock, the log of real per capita government spending and the log of real per capita consumption for individuals belonging to group $j ; A^{j}(L)=$ $A_{0}^{j}+A_{1}^{j} L+\ldots+A_{4}^{j} L^{4}, K^{j}, D_{1}^{j}, D_{2}^{j}$ are vectors of parameters; and $U_{t}^{j}$ is a vector of shocks identified via the recursive ordering procedure, where the SPF shock is ordered first, and consumption last. In our benchmark results we let $D_{1}=D_{2}=0$, as requested by a referee; however, we also discuss results with the quadratic trend, which was included in Ramey's (2011a) original VAR specification. Our VAR is similar to Ramey (2011a) except that she also includes an average tax rate variable and an interest rate variable (we do not include the latter in order to keep our VAR parsimonious, due to small sample concerns). By using a SVAR model where the shock is ordered first, we ensure that the shock series is orthogonal to past information contained in the other variables included in the VAR; at the same time, we allow variables other than the shock to contemporaneously react to the shock itself. Our choice of lag length is similar to Ramey (2011a).

The next section reports estimated impulse responses (IRFs) to a positive government 
spending policy shock. ${ }^{5}$ We also calculate peak responses that measure the effect of the policy shock and can be interpreted as a multiplier measure - see Spilimbergo et al. (2009) and Ramey (2011a). The peak multiplier is: $\max _{h}\left|\frac{\partial \ln C_{t+h}}{\partial \ln G_{t}} \frac{\bar{C}}{\bar{G}}\right| \operatorname{sign}\left(\frac{\partial \ln C_{t+h}}{\partial \ln G_{t}}\right)$, where $C_{t}$ is aggregate consumption at time $t, G_{t}$ is government spending, and $\bar{G}$ and $\bar{C}$ are the average government spending and consumption values over the entire time series. Furthermore, we normalize the impact response of $G_{t}$ to the fiscal policy shock to be unity, so we can interpret the impulse-responses of consumption at horizon $h$ (reported in the figures) to be the $h$-period multiplier (although not rescaled by the long-run values of $G_{t}$ and $C_{t}$ ).

\section{HETEROGENEITY IN INDIVIDUALS' RESPONSES TO GOVERNMENT SPEND-}

\section{ING POLICY SHOCKS}

This section presents the main empirical results for the responses to a government spending shock. To preview our results, in general we find substantial empirical evidence in favor of heterogeneity across consumers' responses to an aggregate positive government spending policy shock. In particular, our main results show that the poorest and the oldest individuals' consumption levels are the most positively affected by the shock. We also find that consumption of the working group as well as the wealthiest individuals is the most negatively affected by the government spending policy shock. ${ }^{6}$

Impulse responses for consumption of individuals grouped by income quintiles are dis-

\footnotetext{
${ }^{5}$ The figures also report $68 \%$ standard error bands, as in Ramey (2011a), calculated using a residual-based parametric bootstrap (Berkowitz and Kilian, 2000).

${ }^{6}$ Note that it is unlikely that our results are driven by a homogeneous response to a heterogeneous fiscal policy shock rather than being heterogeneous responses to a homogeneous fiscal policy shock (as we argue) since the CEX is a random sample and the fiscal shock measure is aggregate.
} 
played in Figure 1. It is noteworthy that the richest quintiles are hurt the most in terms of consumption by the increase in government spending, while consumption of the poorest increases instead. Table 1, Panel A, reports peak multipliers. The multipliers are negative for the richest groups and positive for the poorest groups, increasing almost monotonically across groups. ${ }^{7}$ Our results have important implications for the existing debate of the effects of government spending shocks - see Engemann, Owyang and Zubairy (2008) for a survey of the debate. In fact, theoretical models have very different implications regarding the effects of government spending shocks on consumption. According to standard RBC models, consumption should decrease after a permanent positive government spending shock, whereas consumption should increase in the textbook IS-LM model. In fact, according to the standard RBC model, households anticipate the higher taxes that are necessary to repay the (non-productive) government spending, which lowers the net present value of after tax income and generates a negative wealth effect. Therefore, they react to the increase in government spending by lowering their consumption and their leisure. On the other hand, in the IS-LM model, consumers behave in a non-Ricardian fashion and real disposable income is the most important variable affecting consumption. This is because individuals' consumption is a function of their current income and not of their life-time resources. For example, in the presence of credit constraints, we should observe that the increase in government spending causes consumption to increase. Gali et al. (2007) show that a New Keynesian

\footnotetext{
${ }^{7}$ The multipliers are in unit terms. That is, a dollar increase in government spending leads to an increase in consumption equal to the value of the multiplier. Unreported results show that the richest group' multipliers are statistically different from those of the poorest groups, while the significance of the results for age groups is weaker.
} 
model where a fraction of households consume all their income in every period can explain how consumption increases after a government spending shock. ${ }^{8}$ In our analysis, we are able to disentangle the consequences of government spending shocks on consumers with different levels of income, and therefore, facing different levels of credit constraints. Consumers in the poorest income quantiles, which are more likely to be credit constrained, end up increasing consumption. On the other hand, consumers in the richest income quantiles, which are less likely to be credit constrained, end up decreasing consumption, as the theory predicts.

The reason we claim that poorest individuals are more likely to be credit constrained is the empirical evidence in Attanasio et al. (2008), according to which low income consumers are substantially more credit constrained than high income consumers. Interestingly, we find that approximately $20 \%$ of consumers (the wealthiest) decrease their consumption after a government spending shock, and hence are estimated not to be credit constrained. This estimate is very similar to that reported in Attanasio et al. (2008) for CEX data, according to which approximately $15 \%$ of the population with the highest income is not liquidity constrained.

Finally, note that, typically, the richest individuals have higher consumption levels than poorer individuals, which is true in our data as well. Fiscal shocks, by increasing consumption of the poorest and decreasing consumption of the richest, overall tend to decrease consumption heterogeneity.

We also investigate responses based on age groups. Figure 2 shows the IRF of consump-

\footnotetext{
${ }^{8}$ Gali et al. (2007) show that another necessary condition for consumption to rise in response to a fiscal expansion is price stickiness in goods markets as well as, in one version of their model, imperfectly competitive labor markets.
} 
tion for individuals grouped by age. The age groups that are most negatively, persistently and significantly affected by the fiscal shock are the third and fourth quintiles, which correspond to people aged 35 to 70, who are possibly in wealthiest period of their lives. The oldest category, instead, has a significantly positive increase in consumption on impact; we conjecture that individuals start to decumulate their wealth when retiring, and might behave more like hand-to-mouth consumers. Panel B in Table 1 provides additional results by reporting the peak multiplier of consumption for each group. The middle age groups have the most negative peak multiplier. The oldest category has a positive peak response. Note that the youngest group has a negative impact response, but the peak multiplier is positive as the largest response in magnitude occurs after two periods and it is positive. Overall, these results provide empirical evidence that age may also matter in the response to a government spending shock.

Table 2 shows that our main conclusions are robust to quadratic detrending. In Anderson et al. (2015), we also show that an additional benefit of using household level data is that we can control the aggregation process, which enables us to avoid the aggregation bias that might be present when working with aggregate data. We find that aggregate IRFs based on disaggregate CEX data based on disaggregated data behave differently from traditional IRFs based on aggregate data. In particular, traditionally aggregated CEX data show a delayed and significant decrease in aggregate consumption after a government spending shock, which instead tends to be smaller or even positive according to our aggregate CEX measure. We also show that our empirical results are robust to enlarging the VAR with more variables. 


\section{CONCLUSIONS}

Our empirical results uncover interesting differences in disaggregate individuals' consumption responses to government spending shocks, which would not be possible to uncover in traditional analyses based on aggregate data.

In particular, unexpected increases in government spending hurt the working-age and the wealthiest individual the most in terms of consumption. The wealthiest experience the highest cumulative drop in consumption whereas consumption of the poorest increases significantly. Thus, government spending policy shocks tend to decrease consumption inequality.

These results suggest that it is important to allow for heterogeneity in individuals' behavior when studying the effects of fiscal policy shocks. Existing theoretical models suggest that fiscal shocks may have very different effects on consumption depending on whether consumers are credit constrained. Our empirical results show that indeed individuals respond to shocks differently depending on their wealth; this finding highlights the fact that, indeed, consumers who are most likely credit constrained do increase their consumption after an unexpected increase in government spending. As we show, these interesting results are in line with theoretical macroeconomic models that allow for a fraction of consumers to be credit constrained.

Note that our results depend on the VAR specification and choice of variables we make. Considering VARs with a large number of variables is beyond the scope of our paper. In a

recent paper, De Giorgi and Gambetti (2012) consider factor models to extract information on the state of the macroeconomy. It could be interesting to consider large dimensional VARs, although we leave it for future research. 


\section{REFERENCES}

Anderson, Emily, Atsushi Inoue, and Barbara Rossi. (2015) "Heterogeneous Consumers and Fiscal Policy Shocks." Barcelona GSE Working Paper No. 822.

Attanasio, Orazio, and Guglielmo Weber. (1993) "Consumption, the Interest Rate and Aggregation." Review of Economic Studies, 60(3), 631-649.

Attanasio, Orazio, Penelopi Goldberg, and Ekaterini Kyriazidou. (2008) "Credit Constraints in the Market for Consumer Durables: Evidence from Micro Data on Car Loans." International Economic Review, 49(2), 401-436.

Berkowitz, Jeremy, and Lutz Kilian (2000). "Recent Developments in Bootstrapping Time Series." Econometric Reviews, 19(1), 1-48.

Burnside, Craig, Martin Eichenbaum, and Jonas Fisher. (2004) "Fiscal Shocks and Their Consequences." Journal of Economic Theory, 115, 89-117.

Cavallo, Michele. (2005) "Government Employment Expenditure and the Effects of Fiscal Policy Shocks." Federal Reserve Bank of San Francisco Working Paper 2005-16.

Deaton, Angus. (1985) "Panel Data from Time Series of Cross Sections." Journal of Econometrics, 30(1-2), 109-126.

De Giorgi, Giacomo and Luca Gambetti. (2012) "The Effects of Government Spending on the Distribution of Consumption.". Mimeo.

Edelberg, Wendy, Martin Eichenbaum, and Jonas Fisher. (1999) "Understanding the Effects of a Shock to Government Purchases." Review of Economic Dynamics, 2(1), 166206.

Engemann, Kristine, Michael Owyang, and Sarah Zubairy. (2008) "A Primer on the 
Empirical Identification of Government Spending Shocks." Federal Reserve Bank of St. Louis Review 90(2).

Gali, Jordi, David López-Salido, and Javier Vallés. (2007) "Understanding the Effects of Government Spending on Consumption." Journal of the European Economic Association, $5(1), 227-270$.

Giavazzi, Francesco, and Michael McMahon. (2012) "The Household Effects of Government Consumption." In: Alesina, A. and F. Giavazzi (eds.), Fiscal Policy After the Crisis, Chicago: University of Chicago Press and NBER, 103-141.

Heathcote, Jonathan. (2005) "Fiscal Policy with Heterogeneous Agents and Incomplete Markets." Review of Economic Studies, 72(1), 161-88.

Inoue, Atsushi, Lutz Kilian and Fatma Burcu Kiraz. (2009) "Do Actions Speak Louder Than Words? Household Expectations of Inflation Based on Micro Consumption Data." Journal of Money, Credit and Banking, 41(7), 1331-1363.

Johnson, David, Jonathan Parker, and Nicholas Souleles. (2006) "Household Expenditure and the Income Tax Rebates of 2001." American Economic Review, 96(5), 1589-1610.

Krusell, Per and Anthony Smith. (1998) "Income and Wealth Heterogeneity in the Macroeconomy." Journal of Political Economy, 106(5), 867-96.

Lusardi, Annamaria. (1996) "Permanent Income, Current Income, and Consumption: Evidence from Two Panel Data Sets." Journal of Business and Economic Statistics, 14(1), $81-90$.

Nekarda, Christopher J., and Valerie A. Ramey. (2011) "Industry Evidence on the Effects of Government Spending." American Economic Journal Macroeconomics, 3(1), 36-59. 
Owyang, Michael, and Sarah Zubairy. (2009) "Who Benefits From Increased Government Spending? A State-Level Analysis." Regional Science and Urban Economics, 43(3), 445-464. Perotti, Roberto. (2007) "In Search of the Transmission Mechanism of Fiscal Policy." NBER Macroeconomics Annual 22, 169-226.

Ramey, Valerie A., and Matthew Shapiro. (1998) "Costly Capital Reallocation and the Effects of Government Spending." Carnegie Rochester Conference on Public Policy, 48(1), 145-194.

Ramey, Valerie A. (2009) "Defense News Shocks, 1939-2008: An Analysis Based on News Sources." UCSD manuscript.

Ramey, Valerie A. (2011a) "Identifying Government Spending Shocks: It's All in the Timing." Quarterly Journal of Economics, 126(1), 1-50.

Ramey, Valerie A. (2011b) "Can Government Purchases Stimulate the Economy?" Journal of Economic Literature, 49(3), 673-85.

Rios-Rull, Jose'. (1995). "Models with Heterogeneous Agents." in: Thomas Cooley (ed.), Frontiers of Business Cycles Research, Princeton (NJ): Princeton University Press, Chp. IV.

Rossi, Barbara, and Sarah Zubairy. (2011) "What is the Importance of Monetary and Fiscal Shocks in Explaining US Macroeconomic Fluctuations?" Journal of Money, Credit and Banking, 43(6), 1247-1270.

Schmitt-Grohe, Stephanie, and Martin Uribe. (2012) "What's News in Business Cycles." Econometrica, 80(6), 2733-2764.

Zubairy, Sarah. (2011) "Explaining the Effects of Government Spending Shocks." Mimeo, Bank of Canada. 


\section{TABLES AND FIGURES}

Table 1. Multipliers in Benchmark VAR Without Trend

\begin{tabular}{|c|c|c|c|c|c|c|}
\hline & \multicolumn{3}{|c|}{ Panel A. Income Groups } & \multicolumn{3}{|c|}{ Panel B. Age Groups } \\
\hline & Peak IRF & $\mathrm{h}$ & $68 \%$ C.I. & Peak IRF & $\mathrm{h}$ & 68\% C.I. \\
\hline $1^{s t}$ Quintile & -1.71 & 1 & $(-2.83 ;-1.16)$ & 1.39 & 2 & $(-2.83 ; 2.99)$ \\
\hline $2^{n d}$ Quintile & -1.09 & 4 & $(-2.08 ;-0.46)$ & -1.07 & 1 & $(-2.13 ; 1.06)$ \\
\hline $3^{r d}$ Quintile & -1.17 & 2 & $(-2.20 ; 1.12)$ & -1.03 & 1 & $(-2.26 ;-0.82)$ \\
\hline $4^{t h}$ Quintile & 0.87 & 4 & $(-1.10 ; 2.00)$ & -0.73 & 1 & $(-1.66 ;-0.48)$ \\
\hline $5^{\text {th }}$ Quintile & 1.17 & 3 & $(-1.34 ; 2.48)$ & 1.32 & 0 & $(-1.81 ; 2.53)$ \\
\hline
\end{tabular}

Table 2. Multipliers in Benchmark VAR With Trend

\begin{tabular}{|c|c|c|c|c|c|c|}
\hline & \multicolumn{3}{|c|}{ Panel A. Income Groups } & \multicolumn{3}{|c|}{ Panel B. Age Groups } \\
\hline & Peak IRF & $h$ & $68 \%$ C.I. & Peak IRF & $h$ & $68 \%$ C.I. \\
\hline $1^{s t}$ Quintile & -1.09 & 1 & $(-1.95 ; 0.73)$ & 1.49 & 2 & $(-2.86 ; 3.08)$ \\
\hline $2^{\text {nd }}$ Quintile & -0.64 & 4 & $(-1.42 ; 1.12)$ & -0.63 & 1 & $(-1.47 ; 1.45)$ \\
\hline $3^{r d}$ Quintile & 0.80 & 3 & $(-1.19 ; 1.77)$ & -0.78 & 1 & $(-1.88 ;-0.45)$ \\
\hline $4^{\text {th }}$ Quintile & 0.88 & 3 & $(-0.89 ; 1.86)$ & -0.35 & 0 & $(-1.15 ; 0.62)$ \\
\hline $5^{\text {th }}$ Quintile & 1.74 & 3 & $(-1.21 ; 2.85)$ & 1.68 & 0 & $(-1.78 ; 2.70)$ \\
\hline
\end{tabular}

Notes to the Tables. The tables report the peak multiplier of nondurable consumption to a government spending policy shock for individuals sorted according to their income (Panel A) and age (Panel B); $h$ is the horizon of the peak multiplier; $68 \%$ confidence bands are reported in parentheses. 
Figure 1. Impulse Responses of Nondurable Consumption

\section{by Income Group}
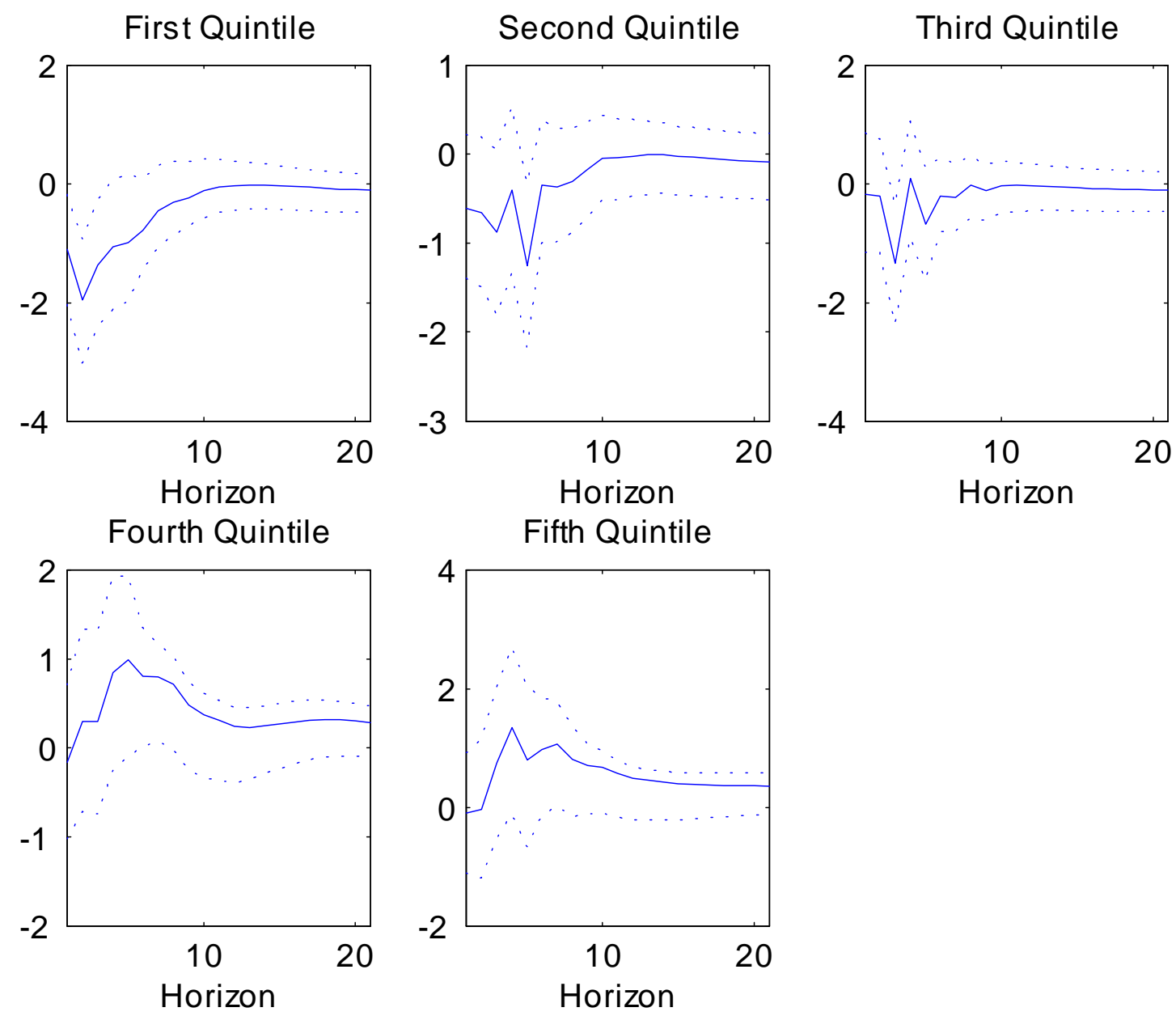

Notes to the Figure. The figure reports the response of nondurable consumption for various income groups in CEX data with $68 \%$ confidence bands. The richest group is depicted in the top left panel, labeled "First Quintile"; the second richest group is depicted in the top middle panel, labeled "Second Quintile"; and so forth, until the poorest group, depicted in the bottom right panel, labeled "Fifth Quintile". The VAR is estimated without a deterministic nor quadratic time trend. 
Figure 2. Impulse Responses of Nondurable Consumption by Age Group
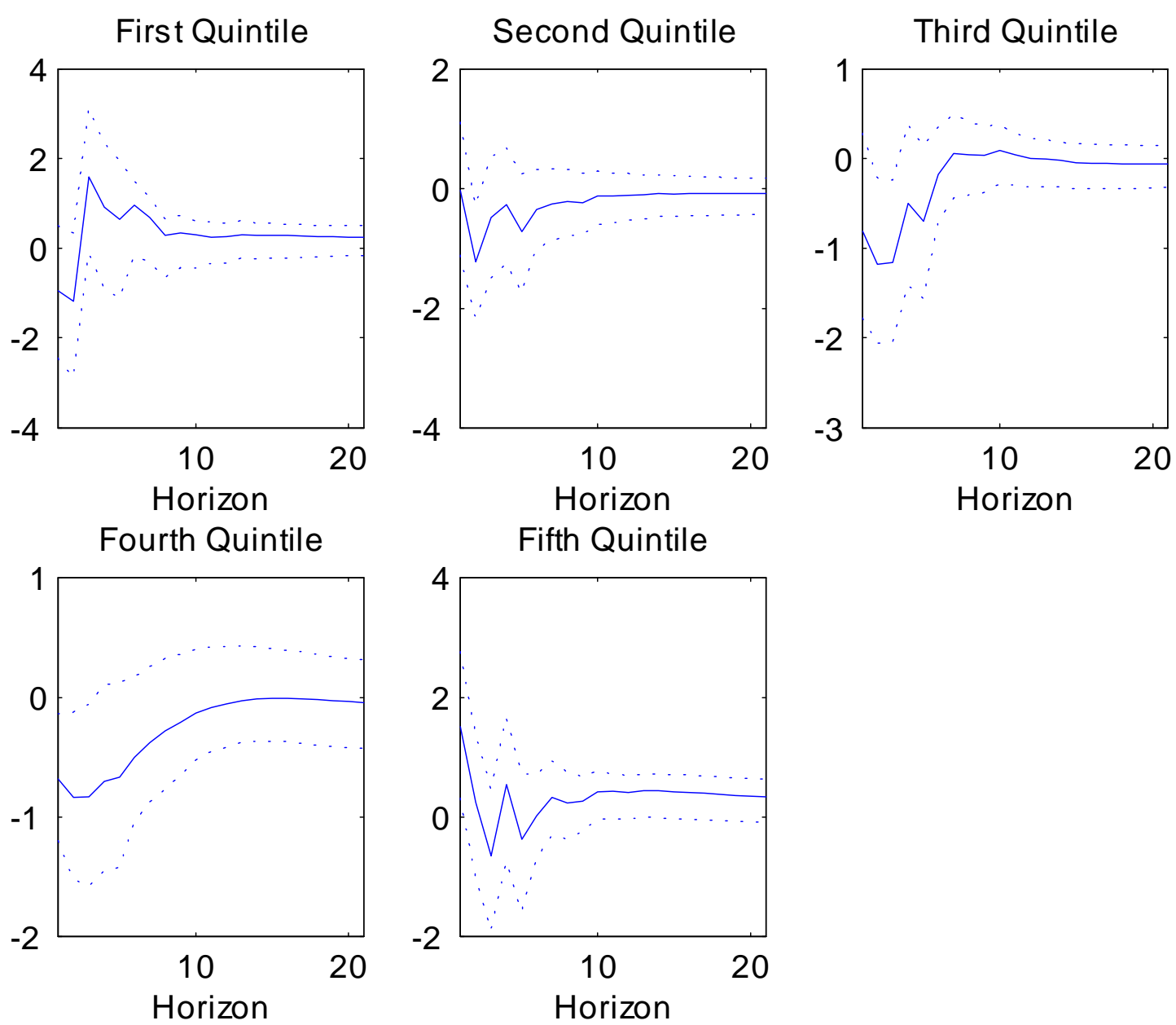

Notes to the Figure. The figure reports the response of nondurable consumption for various age groups in CEX data with $68 \%$ confidence bands. The youngest group is depicted in the top left panel, labeled "First Quintile"; the second youngest group is depicted in the top middle panel, labeled "Second Quintile"; and so forth, until the oldest group, depicted in the bottom right panel, labeled "Fifth Quintile". The VAR is estimated without a deterministic nor quadratic time trend. 